\title{
Revisitando as influências das agências internacionais na origem dos conselhos de políticas públicas
}

\author{
Reexamining the International Agencies influences \\ in the origin of the public-policy councils
}

\author{
Natalina Ribeiro ** \\ Raquel Raichelis ${ }^{* *}$
}

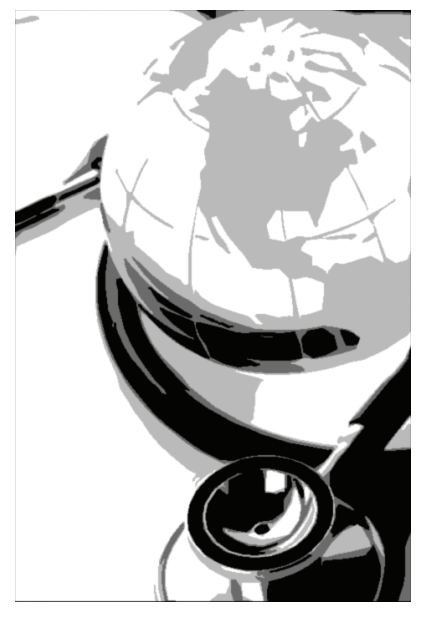

"Estudar as determinações mais gerais, internacionais, regionais, nacionais não prejudica as ações cotidianas. Ao contrário, fornece o necessário contexto de referência.” Ermínia Maricato - O impasse da política urbana no Brasil

Resumo: Este artigo tem como objetivo aprofundar o debate acerca da influência exercida pelas agências internacionais nos processos que deram origem aos conselhos de políticas públicas no Brasil como canais institucionais de participação. Situa a intensa atividade internacional do final da Segunda Guerra Mundial e a criação dos organismos multilaterais. Detém-se na reflexão sobre o papel das agências internacionais na área da saúde no Brasil, buscando reconstruir as orientações que incidiram no estímulo a estratégias participativas nas políticas públicas, que culminaram com a criação dos conselhos de saúde, referência inaugural para outras áreas implantarem seus sistemas descentralizados e participativos.

Palavras-chave: Conselhos, Políticas Públicas. Agências Internacionais. Sujeitos Coletivos. Participação Institucional. Política de Saúde.

* Este texto tem como referência direta a tese de doutorado de Natalina Ribeiro, com o título. Sujeitos e projetos em disputa na origem dos conselhos de políticas públicas, defendida no Programa de Estudos Pós-Graduados em Serviço Social da PUC-SP, em 2011, sob orientação da profa. dra. Raquel Raichelis.

** Doutora em Serviço Social e consultora em processos de formação política. Graduada pela Universidade Estadual de Londrina (UEL)/PR, Brasil, mestrado e doutorado pela PUC-SP.E-mail: ribeiro.natalina@ gmail.com

*** Doutora em Serviço Social e professora do Programa de Estudos Pós-Graduados em Serviço Social da PUC-SP/São Paulo, Brasil.E-mail: raichelis@uol.com.br 


\begin{abstract}
This article aims at deepening the debate on the influence of international agencies in the processes that gave rise to the councils of public policies as institutional channels of participation in Brazil. It focuses on the intense international activity at the end of World War II and the creation of multilateral institutions. It contemplates the international agencies'role in the field of health policies in Brazil, and it seeks to reconstruct the guidelines that focused on the stimulation of participatory strategies that led to the creation of health councils, which were the first reference for other areas to implement their decentralized and participatory systems.
\end{abstract}

Keywords: Councils. Public policy. International agencies. Collective subjects. Institutional participation. Health policy.

\title{
Introdução
}

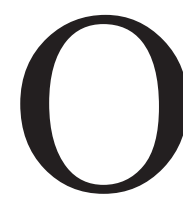

s conselhos de políticas públicas, com as características existentes atualmente, foram criados a partir das regulamentações da Constituição Federal de 1988 (CF88). Sua origem é frequentemente vinculada às influências das experiências socialistas, das agências internacionais e dos movimentos sociais surgidos dos processos reivindicatórios ao longo dos anos 1970. Os conselhos da área da saúde, os primeiros a ser regulamentados, são apontados como principal referência adotada pelos demais conselhos de políticas públicas e defesa de direitos.

Este artigo tem como objetivo aprofundar o debate acerca da influência exercida pelas agências internacionais nos processos que deram origem a esses canais institucionais de participação. $\mathrm{O}$ tema tem sido citado na literatura sobre a experiência conselhista brasileira, mas ainda persistem lacunas sobre as dinâmicas dos cenários mais amplos, no espaço e no tempo, que permitam conhecer por onde e como circularam as ideias, ideais e conceitos presentes nas trajetórias de disputas pela construção democrática no Brasil.

O papel desempenhado pelas agências internacionais nos rumos assumidos pelas políticas públicas tem sido enfatizado em vários estudos (cf. Raichelis e Evangelista, 2009), veiculando

um novo discurso político de revalorização do lugar da sociedade civil na gestão pública e na governabilidade democrática. No entanto, essa postura de estímulo à participação da sociedade civil também encobre, através de uma aparente homogeneidade, a diversidade de concepções, intenções e projetos, situação que se reproduz também no interior de todas as instâncias societárias. (Idem, p. 17-18) 
"Nunca fomos tão participativos" é o título de um texto de Maricato (2011) ao constatar como a participação democrática é tema presente em todas as agendas de diferentes instituições e organizações não governamentais, nacionais e internacionais, "envolvendo, de preferência, também os pobres da periferia" (2011, p. 89). Mas a autora interpela, ao mesmo tempo, sobre os resultados dessa hegemonia do "participativismo", no sentido de fortalecer o movimento que busca enfrentar as forças políticas que resistem à implementação dos marcos legais conquistados nas lutas, em diferentes políticas sociais.

Considerando esse cenário, entendemos ser relevante revisitar tais referências presentes na origem dos conselhos. Mas por quê?

Em primeiro lugar, pela necessidade de conhecer melhor essa relação, à luz do fato de sermos um país jovem, marcado por um modelo de colonização e inserção dependente no contexto internacional. Por vários caminhos, essa gênese naturalizou a importação de modelos de desenvolvimento econômico, político e social, reafirmando a relação de dependência com os países desenvolvidos. Em segundo lugar, porque a heterogeneidade de conselhos existentes atualmente não pode ser compreendida apenas nos limites das disputas políticas internas ao país, sem a ampliação de cenários, sujeitos e interesses condicionantes dos diferentes processos apenas indicados na origem dos conselhos. $\mathrm{Ou}$ seja, revisitar as referências aparentes nas tramas históricas constitutivas desses canais institucionais de participação implica o esforço de aproximação aos nexos e relações desse objeto particular à totalidade na qual está imerso. Para tanto, sem a pretensão de esgotar a pauta dos temas a ser aprofundados, mas esperando contribuir com novos aportes, apresentamos os principais aspectos verificados nas dinâmicas das referências internacionais que podem oferecer elementos à reflexão sobre o lugar e o os desafios dos conselhos na disputa pela construção democrática no Brasil.

\section{Referências internacionais - a presença das agências internacionais na gênese dos conselhos}

Pesquisadores e estudiosos do tema (Côrtes, 1996; Serapioni, 2004; Teixeira, 2001) identificam dois blocos de referências internacionais com influência nos processos que deram origem aos conselhos de políticas públicas no Brasil. No primeiro bloco estão as experiências conselhistas de orientação so- 
cialista, inspiradas especialmente na Comuna de Paris (1871) e nos soviets russos (1905) que, no final dos anos 1970, também influenciaram o surgimento dos conselhos populares no Brasil. ${ }^{1}$ No segundo se encontram as orientações emitidas pelas agências internacionais que compõem o Sistema de Organização das Nações Unidas (ONU) e aquelas criadas a partir da Conferência de Bretton Woods: Banco Mundial (BM) e Fundo Monetário Internacional (FMI), e que serão privilegiadas neste artigo.

A literatura acerca da origem dos conselhos gestores no Brasil (Côrtes, 1996; Serapioni, 2010; Teixeira, 2001) traz citações sobre o papel desempenhado, a partir dos anos 1950, pelas recomendações das agências internacionais nas decisões do governo brasileiro, especialmente quanto à introdução do modelo de desenvolvimento adotado nos países hegemônicos do mundo capitalista. No entanto, ainda faltam informações sistematizadas para uma aproximação aos caminhos e conexões por meio dos quais as orientações desses organismos internacionais teriam influenciado nos processos participativos, desencadeados durante o período de luta pela democratização brasileira e que desembocaram na inscrição dos conselhos na CF88. A busca dessas referências revelou intensas atividades no cenário internacional, provocadas pelas crises econômicas mundiais, a destruição dos países que foram palco da Segunda Guerra Mundial (GM) e as disputas políticas e ideológicas no período da Guerra Fria (1946-89). Apesar de nenhum país em qualquer continente passar incólume aos efeitos produzidos por esses eventos, a condução do novo arranjo geopolítico mundial foi protagonizado pelos chamados países desenvolvidos, principalmente EUA e Inglaterra, em disputa pela hegemonia global.

O fato mais significativo no reordenamento da economia internacional desse período aconteceu ainda durante a II GM, a partir dos acordos firmados na Conferência de Bretton Woods, em 1944, com a criação do FMI e do BM.

O fundamental desses acordos foi dirimir a rivalidade e a luta na cúpula que se travou entre o velho imperialismo inglês e o emergente norte-americano para definir as novas regras de jogo no sistema financeiro internacional. (Baer e Lichtensztejn, 1987, p. 27)

A partir desse evento, a economia mundial restabelece o ouro como medida de conversão das moedas nacionais. Ocorre que apenas os Estados Unidos

1. Para aprofundamento, consultar Ribeiro (2011). 
possuem reservas capazes de garantir tal conversibilidade, transformando o dólar na "divisa-chave e a moeda de reserva obrigatória no sistema financeiro internacional e no Fundo" (Idem, p. 29). A adoção do padrão monetário internacional sob hegemonia norte americana foi possível dada à fragilidade das economias europeias desde a grande crise de 1929, agravada pela destruição provocada durante a Segunda Guerra Mundial.

A Conferência de Bretton Woods significou a "queda de braço" entre Inglaterra e Estados Unidos. O confronto entre os planos Keynes e White, com expressiva vitória do último (e dos EUA), é descrito pelos autores como uma negociação desigual entre os dois países. Desigual porque, ao final da Segunda Guerra Mundial, a Inglaterra dependia de empréstimos dos Estados Unidos para reconstruir o país e seu parque industrial. Da mesma forma, os países da Europa Ocidental e o Japão "se viram obrigados a aceitar a hegemonia política, econômica e financeira dos Estados Unidos, enquanto parte da Europa Central e Oriental mudava de regime político, sob a hegemonia da URSS" (Gadelha, 2002, p. 256).

A principal divergência entre os planos Keynes e White, ${ }^{2}$ e talvez o maior constrangimento imposto pela hegemonia norte-americana aos demais países signatários da Conferência de Bretton Woods girou em torno da aplicação dos mecanismos de ajuste da balança de pagamentos. O que parece uma clara expressão do poder americano de impor exigências e a defesa unilateral de seus interesses no acordo celebrado no Plano White e inscrito nos estatutos do FMI está no fato de que este "só criou obrigações e condições concretas de ajuste para os países deficitários” (Baer e Lichtensztejn, 1987, p. 31). Significa dizer que os Estados Unidos não estavam submetidos à prestação de contas e ajustes impostos aos países que necessitavam empréstimos do FMI.

As tarefas atribuídas ao BM foram delimitadas aos objetivos de reconstrução dos países destruídos pela guerra, fomento ao desenvolvimento e estabilização econômica mundial. Sendo o mercado financeiro norte-americano a principal fonte da provisão de recursos do Banco, não houve questionamentos à autoridade dos Estados Unidos sobre o seu funcionamento, bem como a ingerência dos banqueiros desse país na sua direção (Idem, p. 33).

2. Hobsbawm (2006, p. 269) também se refere à disputa sobre o FMI entre os economistas representantes da Grã-Bretanha (Keynes) e EUA (White). 
Não vamos detalhar as funções e dinâmicas de funcionamento desses organismos, apenas exemplificar o que anteriormente chamamos de intensa atividade no cenário internacional. Aqui, cabe destacar a criação do FMI com objetivos principais de garantir a estabilidade financeira mundial, realizar empréstimos a curto prazo aos países-membros quando enfrentassem dificuldades internas e zelar pela implementação do novo padrão monetário. Inicialmente ao BM caberia oferecer recursos financeiros aos países destruídos pela II GM, bem como o financiamento a longo prazo de projetos de desenvolvimento dos países-membros. Logo, as atividades desses organismos internacionais passaram a se preocupar também em impulsionar modelos de desenvolvimento nos países do Terceiro Mundo, gerando como efeitos colaterais as dívidas externas e o aprofundamento da relação de dependência na qual ainda se encontram vários dos chamados países da periferia capitalista. Assim, o suporte financeiro aportado a esses países estava vinculado a condicionalidades da adoção de medidas e recomendações macroeconômicas e estruturais, consolidando a relação "centro-periferia" e a hegemonia de interesses dos países industrializados. Entre as medidas sugeridas para implementar as recomendações constava a adoção de diversas modalidades de participação da população ou da comunidade, referendando a perspectiva da democracia liberal de redução dos custos sociais na prestação de serviços público.

Também por iniciativa dos EUA, em 1945, é criada a ONU, formada por organismos multilaterais voltados principalmente para a garantia da ordem e da paz mundial, bem como facilitação das relações internacionais. Constituindo o chamado Sistema ONU foram criadas agências internacionais, fundos e programas voltados para temas específicos, como a Organização Internacional do Trabalho - OIT e o Fundo das Nações Unidas para a Infância - Unicef, criados em 1946, a Organização Mundial da Saúde — OMS, 1948, e o Programa das Nações Unidas para Desenvolvimento - PNUD, 1965. Cada organismo da ONU é constituído por pelo menos três países, os chamados países-membros, responsáveis por elaborar recomendações em torno de políticas nacionais de desenvolvimento em suas áreas de especialização. As agências internacionais são constituídas com base nos acordos estabelecidos entre os vários governos que as compõem e estabelecem em comum as definições de missão, regras de atuação e origem de recursos financeiros.

Importa destacar que os organismos do Sistema ONU e as instituições de Bretton Woods apresentam ao menos uma diferença substancial na sua estrutu- 
ra de funcionamento. As nações representadas nas agências, programas e fundos da ONU têm igual poder de voto nas decisões dos organismos onde participam. Já as organizações de Bretton Woods definem o peso de cada país-membro nos processos de decisão, de acordo com a proporcionalidade da sua participação na composição dos recursos financeiros da agência. Embora o poder econômico também determine a capacidade de influenciar decisões nos organismos onde este não é o critério estipulado, a necessidade de recorrer a doações voluntárias para o financiamento de projetos específicos amplia a ascendência dos países com maior disponibilidade de recursos sobre os demais.

As iniciativas dos EUA não se restringiram ao continente europeu, e a construção do seu projeto de hegemonia previa ampliar sua atuação também junto aos "países pobres". A partir dessa perspectiva, em 1948 promove a alteração na nomenclatura e competências da União Internacional das Repúblicas Americanas, criada em 1890, que passa a ser denominada Organização dos Estados Americanos (OEA) e assume o papel de principal fórum multilateral latino-americano de discussões das questões de maior relevância para os países da região (Silva, 2008, p. 73).

No final dos anos 1950 e início dos 1960, o governo dos EUA intensifica suas atenções para a dinâmica econômica e política na América Latina, onde identificava nos baixos índices de desenvolvimento capitalista e nos "bolsões" de pobreza os elementos facilitadores de disseminação da ideologia comunista. Alarmado com a Revolução Cubana (1959), o governo norte-americano passa então a promover iniciativas voltadas a influenciar a dinâmica econômica, política, social e cultural nos países vizinhos, como estratégia de combate ao avanço do "inimigo". A batalha continua sendo travada principalmente com a criação de novas instituições multi ou bilaterais, sempre em ações combinadas e complementares com bancos e empresas transnacionais. A agenda política contemplou a criação do Banco Interamericano de Desenvolvimento (BID, 1959) a fim de obter recursos externos voltados para oferecer financiamento ao desenvolvimento econômico, social e institucional na região e promover a integração regional.

Durante encontro realizado no Uruguai, em 1961, o presidente Kennedy lança a "Aliança para o Progresso", do qual participaram autoridades de todo o continente, inclusive o representante de Cuba, Ernesto Che Guevara, o único a se opor aos termos da Aliança. A principal intenção dessa iniciativa foi claramente conter o avanço comunista na América Latina, a partir da vitória de Fidel 
em Cuba, e visava a travar o embate ideológico por intermédio do apoio ao desenvolvimento econômico na região. Ainda em 1961, o Congresso norte-americano aprovou a criação da Agency for International Development (AID), no âmbito do Banco Mundial, com o objetivo de conceder empréstimos a longo prazo aos países em desenvolvimento sem cobrança de juros. À AID, também conhecida por AIF ou Usaid, denominação mais popularizada na América Latina, coube executar o programa da "Aliança para o Progresso" por meio do financiamento e apoio às campanhas "educativas" e gestão da assistência econômica às suas ações (Baer e Lichtensztejn, 1987; Mattos, 2001; Silva, 2008). Foram investidos fartos recursos na produção de material de propaganda anticomunista e na formação de intelectuais latino-americanos, especialmente professores do ensino fundamental.

As iniciativas apoiadas e financiadas por organismos articulados na "Aliança para o Progresso" são descritas por Ugalde (1985) como responsáveis por destruir importantes valores e tradições de povos indígenas e camponeses latino-americanos, bem como instrumentalizar a participação da comunidade como veículo de promoção da sociedade de consumo, uma vez que mudanças nos valores das comunidades tradicionais favoreceriam a exportação de bens de capital e a exploração do trabalho "moderno" pela "burguesia nacional”. Segundo Ugalde, além de utilizado como instrumento de cooptação das lideranças tradicionais, o estímulo à participação da comunidade em programas de autoconstrução de equipamentos públicos, infraestrutura, sistemas de irrigação e habitação, entre outros, permitiu a canalização de recursos financeiros para o desenvolvimento de infraestrutura urbana em benefício das elites rurais e urbanas, tais como: aeroportos, agronegócios, universidades e, inclusive, a aquisição de armas e equipamentos utilizados pela polícia para reprimir organizações e movimentos populares. Segundo o autor, a iniciativa contou também com o apoio de diversos empresários brasileiros articulados por intermédio do Instituto de Pesquisas e Estudos Sociais (Ipes).

A análise dessas iniciativas institucionais permite considerar em que medida o desenho dos sistemas de organizações internacionais constituídos em torno da ONU e da Conferência de Bretton Woods representavam parte do projeto político de hegemonia mundial almejado pelo governo americano. Ao constituir canais de repasse direto de recursos em forma de empréstimos ou doações aos países em dificuldades, o governo norte-americano fortaleceu sua 
posição e a defesa dos seus interesses no cenário global com relativa autonomia em relação aos demais países desenvolvidos.

A heterogeneidade verificada na composição e finalidades dos organismos internacionais fornece indícios quanto à impossibilidade de tratar em bloco a atuação das agências. Não apenas em função das diferenças referentes à origem (Bretton Woods ou sistema ONU), mas também a partir das características observadas no curso desenhado pelas mudanças nas orientações e prioridades definidas a cada contexto histórico.

A multiplicidade de organismos criados após a Segunda Guerra Mundial desempenhou importante papel na estratégia de consolidar a internacionalização do sistema econômico vigente. Nas democracias modernas, os governos são transitórios com alternância prevista a cada quatro ou cinco anos, de acordo com as Constituições nacionais. As estruturas das instituições são permanentes e oferecem possibilidades de fixar concepções, valores e interesses, dos quais são instrumentos de implementação e sedimentam dinâmicas próprias de funcionamento, apesar ou com o apoio dos governos "de plantão".

A partir dessa perspectiva, vamos delinear elementos do percurso de mudanças nas estratégias e orientações impressas pelas agências internacionais, buscando identificar suas implicações, especialmente para os elementos que interessam ao tema dos conselhos. $\mathrm{O}$ contexto determinante será sempre o movimento assumido pelo sistema de produção capitalista no pós-Segunda Guerra e seus marcos, em torno dos quais existe algum consenso, ao menos entre seus analistas críticos. As agências internacionais moveram-se nesses contextos e atuaram a partir de e sobre seus efeitos. Assim, identificamos três momentos distintos.

No primeiro, do pós-guerra até final dos anos 1960, período de expansão capitalista, o FMI e o BM, norteados pela concepção de desenvolvimento como sinônimo de crescimento econômico, tiveram por objetivo facilitar e apoiar a expansão capitalista por meio de investimentos nas áreas de infraestrutura, desenvolvimento urbano, agricultura, indústria e educação. Por sua vez, as agências do sistema ONU, articuladas em torno de propostas para a implementação de políticas econômicas e sociais de combate à fome e à pobreza, emitiram orientações aos estados nacionais, recomendando a participação da comunidade na implementação de serviços públicos (Côrtes, 1996; Serapioni, 2004; Ugalde, 1985). Nessa primeira fase de criação das agências internacionais, alguns 
países industrializados eram considerados modelos a ser seguidos e a adoção do planejamento, até então instrumento de gestão característico dos países socialistas, passava a compor as orientações das agências internacionais e identificado como principal ferramenta de apoio à estratégia de desenvolvimento (Côrtes, 1996).

No final da década de 1960, marcada por intensas mobilizações sociais e o surgimento dos chamados novos movimentos sociais libertários, entre os quais se destacam as manifestações na França, em maio de 1968, o Sistema ONU passou a ser alvo de questionamentos dos países associados. As orientações emitidas no período anterior produziram resultados indesejados, como a concentração de renda e aglomerações urbanas, causando sérios problemas ambientais e sociais. No campo econômico, geraram desequilíbrios fiscais, como o crescimento das dívidas interna e externa e problemas na balança de pagamentos. Diante desses resultados, os países com maior tradição de industrialização perderam a condição de modelos a serem seguidos e, ao mesmo tempo, os instrumentos de planejamento passaram a ser considerados inoperantes para produzir o desenvolvimento anunciado anteriormente com distribuição de renda e justiça social (Côrtes, 1996).

Nos países centrais, os sindicatos dos trabalhadores pressionavam por melhores salários e questionavam as condições de trabalho impostas pelo modo de produção vigente. Ao mesmo tempo, entravam em cena os movimentos sociais libertários citados anteriormente, que se distinguiam pela orientação anti-institucional e a busca de autonomia frente às instituições políticas tradicionais, em alguns casos incluídos os partidos políticos e sindicatos. Estes últimos poderiam eventualmente compor o quadro de atores para estabelecimento de alianças, mas apenas em caráter esporádico, pois “desconfiavam da ameaça que a institucionalização poderia representar para a autonomia dos movimentos sociais. Ela poderia vir a se constituir numa nova maneira de cooptação pelo establishment" (Côrtes, 1996, p. 31). Da emergência de novos movimentos sociais desiludidos com os mecanismos tradicionais de participação nas democracias liberais surgem as novas lideranças que iriam se envolver nos processos participativos em construção, entre eles os conselhos.

No segundo momento, a "transição crítica" durante a década de 1970 foi marcada pela crise energética, a guerra do Vietnã e a decisão unilateral do governo norte-americano em romper com os acordos de conversibilidade do dólar em ouro. Tal ruptura provocou a valorização do dólar e a atração de investimen- 
tos internacionais, aumentando o custo financeiro dos empréstimos realizados, agravando a situação dos países devedores - com maiores prejuízos para os países em desenvolvimento (Mattos, 2001). Os esforços para estabelecer novo padrão monetário e medidas capazes de controlar a instabilidade monetária e financeira mundial perduraram por toda a década. $\mathrm{O}$ abandono da paridade fixa entre as moedas, associado às políticas de altas taxas de juros e sua aplicação na correção dos empréstimos internacionais, "dotou o sistema de condições propícias para que se desencadeasse uma maior especulação e uma crescente valorização dos capitais financeiros" (Baer e Lichtensztejn, 1987, p. 47).

O declínio da atividade econômica e o endividamento público reduziram a arrecadação dos governos, impondo aos Estados de Bem-estar Social pressões por redução de despesas e racionalização das estruturas burocráticas estatais. As reformas promovidas "implicaram a criação de mecanismos participatórios, os quais poderiam, ao mesmo tempo, exercer pressão e servir como fiscalizadores sobre uma burocracia resistente a mudanças" (Côrtes, 1996, p. 31). Neste contexto, e sob distintas orientações políticas, diferentes propostas de participação foram instituídas. Os governos conservadores apostaram na privatização dos serviços como modelo de reforma do Estado, remetendo o controle da qualidade à lógica das leis do mercado. As reformas de Estado propostas pelos governos social-democratas enfatizavam a necessidade de preservar a noção de provisão pública de bens e serviços. As estratégias reformistas previam a criação de novas formas de participação "para que cidadãos ou usuários expressassem suas opiniões, ampliando o direito dos participantes em manifestar oposição e propor alternativas" (Idem, p. 32).

As propostas de mudanças no modelo de gestão tiveram como propósito oferecer respostas à crise de legitimidade das instituições públicas em meio à morosidade burocrática e às dificuldades financeiras enfrentadas pelos governos. Enquanto a defesa da primeira alternativa esteve a cargo de representantes do capital empenhados na privatização dos serviços públicos, a segunda foi apoiada pelos sindicatos identificados com a luta pela equidade e justiça social (Côrtes, 1996). O embate refletia a dinâmica assumida na luta política polarizada pela "Guerra Fria" e dialogava com a crescente demanda de participação nos processos de tomada de decisão e nos ganhos produzidos pelo desenvolvimento econômico.

Durante a década de 1970, em muitos países (EUA, Canadá, Grã-Bretanha, Espanha, Itália e Alemanha) foram criados e institucionalizados mecanismos 
de participação nas diversas áreas das políticas públicas, especialmente por iniciativa de governos social-democratas, em resposta à intensa demanda por participação direta dos cidadãos no processo político. "A natureza dessa participação variava desde a mera consulta ou advocacia até o envolvimento ativo destes participantes em comitês, comissões e conselhos" (Côrtes, 1996, p. 32).

Sob inspiração participacionista, importantes organizações internacionais como o BM, o BID, a Organização da Agricultura e Alimentação (FAO) e as fundações Milbank, Rockfeller e Kellogg, entre outras, inseriram a noção de participação nos projetos por elas patrocinados, ainda que com distintas concepções. As agências que adotaram a participação como elemento importante para o seu projeto de desenvolvimento são identificadas como exceções. Entre elas, o Instituto de Pesquisas para o Desenvolvimento das Nações Unidas, o Fundo das Nações Unidas para a Infância e a Organização Mundial da Saúde.

Por fim, no terceiro momento, a administração da crise global assume diferentes expressões a partir dos anos 1980 até os dias atuais. Do final dos anos 1970 a meados dos anos 1980 o aprofundamento da crise econômica internacional fragilizou os governos social-democratas e a política de regulação econômica e social desenvolvida pelos Estados de Bem-Estar Social, favorecendo a vitória de políticos conservadores em países importantes como EUA, Grã-Bretanha e Alemanha. Estes países influenciaram as agências internacionais a estimular medidas de ajuste estrutural, onde a participação passava a ser acionada para viabilizar a redução de custos e assumir responsabilidades diretas na prestação de serviços. As agências e os governos que as influenciavam esperavam com o ajuste estrutural reduzir as responsabilidades do aparelho estatal, transferindo a execução de serviços para a sociedade. "O principal interesse dessas agências era o ajustamento estrutural das economias dos países em desenvolvimento através de políticas que visavam reduzir drasticamente o tamanho do aparelho estatal" (Côrtes, 1996, p. 35).

Diante do quadro de crise internacional, o FMI foi forçado a relativizar seus esquemas de ajustes de curto prazo e aproximar-se dos campos de atuação específicos do Banco Mundial. Ao mesmo tempo e também pressionado pela crise, o BM incorporou elementos do ajuste estrutural nas orientações e condicionalidades previstas nos seus empréstimos aos países.

A partir do final da década de 1980, com o acirramento da crise dos Estados de Bem-Estar Social e dos Estados socialistas, a configuração política in- 
ternacional foi amplamente hegemonizada pelos setores conservadores de orientação neoliberal. Ficou claro o esgotamento dos acordos firmados em Bretton Woods, mas suas principais expressões institucionais, BM e FMI, ganharam maior poder na definição de estratégias de desenvolvimento junto aos países subdesenvolvidos (Baer e Lichtensztejn, 1987), demonstrando a capacidade de metamorfose do capital em garantir a manutenção do poder nas mãos dos financiadores, agora preocupados em cobrar a conta dos empréstimos realizados, sem assumir os prejuízos provocados por orientações que não promoveram os resultados anunciados. As recomendações do FMI, consolidadas no documento conhecido como "Consenso de Washington", passaram a orientar a economia mundial, consolidando o ideário neoliberal. Segundo essa cartilha, os países dependentes de aportes do FMI deveriam submeter seu projeto de desenvolvimento a medidas, tais como o rigoroso controle da dívida pública, privatização de empresas estatais e enxugamento das responsabilidades sociais do Estado. A participação da sociedade assumia definitivamente, no discurso oficial, o papel de contribuir com o Estado na racionalização de custos, compartilhando e mesmo assumindo a execução direta de serviços e políticas públicas. No Brasil, essas orientações foram incorporadas pela gestão pública federal a partir de 1990, incidindo sobre as leis de regulamentação dos artigos constitucionais referentes às políticas públicas e à criação dos conselhos.

\section{Atuação das agências internacionais na área da saúde no Brasil}

Apesar da importância assumida pela área da saúde na origem dos conselhos, por seu pioneirismo na implementação de canais de participação, e apesar de frequentes referências à atuação das agências internacionais no processo de elaboração e implementação de políticas de saúde, ainda são escassas as investigações dedicadas à atuação específica dessas organizações (Mattos, 2001). Os estudos produzidos introduzem o tema das agências internacionais ao pesquisarem sobre as origens da participação, mas não apresentam dados aprofundados, tais como a composição de países em distintas conjunturas, suas respectivas orientações políticas e a participação na composição dos fundos de recursos. Ao buscar localizar documentos originais, artigos e outras modalidades de referências sobre o tema, nos deparamos com a situação sobre a qual Mattos alertou. 
O estímulo à participação de cidadãos nos equipamentos de prestação de serviços na área da saúde (hospitais e centros de saúde) é verificado a partir do final dos anos 1960 e início dos 1970. Sua origem é atribuída à pressão dos cidadãos demandando tomar parte nas decisões políticas, mas, conforme afirmamos, também junto à atuação das agências internacionais de desenvolvimento (Côrtes, 1996; Paim, 2007; Serapioni, 2004). A referência para os autores é Ugalde (1985), que localiza na Aliança para o Progresso o marco de maior significado na origem do estímulo ao envolvimento da comunidade nos programas de saúde.

Ugalde (1985) chama a atenção para as semelhanças entre programas de participação comunitária na América Latina, implementados até meados da década de 1970, que já haviam sido observados por Werner:

Surprising similarities exist in the formal and structural details of many of these different government health programs, surprising until one realizes that nearly all of them are aided and monitored by the same small complex of foreign and international agencies: WHO/PAHO, AID, IRDC, IBD, Unicef, FAO, Milbank Foundation, Rockefeller Foundation, Kellogg Foundation etc. (Werner apud Ugalde, 1985, p. 41)

Apesar do diálogo estabelecido com Ugalde, outros autores (Côrtes, 1996; Serapioni, 2004; Mattos, 2001) identificam na Declaração dos Cuidados Primários de Saúde (Unicef/OMS) a principal referência para exemplificar a influência exercida pelas agências internacionais na origem de processos envolvendo a participação de usuários na área da saúde. Elaborada a partir da I Conferência Internacional sobre Cuidados Primários da Saúde, realizada em Alma-Ata (1978), é considerada a contribuição mais efetiva para a consolidação de políticas promotoras da participação comunitária na área da saúde. A Conferência de Alma-Ata é também um marco na área da saúde pública em termos mundiais, por romper com os tradicionais conceitos de saúde: "Pela primeira vez, dependência e pobreza foram ligadas ao estado de saúde, em um documento oficial assinado por vários países e organizações internacionais" (Lima, 2002, p. 3).

A Declaração estabelecia recomendações destacando a necessidade do envolvimento da comunidade nas políticas de cuidados primários de saúde e conclamava a articulação dos governos, organizações internacionais, agências financeiras, entidades multilaterais e bilaterais a apoiar os compromissos ali sintetizados. O pressuposto compartilhado percebia no envolvimento das comunidades a possibilidade de "estabelecer o controle externo sobre as burocracias relutantes em aceitar propostas de mudanças ou reformas no sistema de 
saúde" (Côrtes, 2009, p. 14). As propostas previam, ainda, a utilização de procedimentos básicos,

baseados em métodos e tecnologias práticas, cientificamente bem fundamentadas e socialmente aceitáveis, colocadas ao alcance universal de indivíduos e famílias da comunidade, mediante sua plena participação e a um custo que a comunidade e o país possam manter... (Declaração de Alma-Ata, 1978, p. 1)

A meta "saúde para todos em 2000" era apresentada como um desafio a ser enfrentado, envolvendo todas as áreas das políticas sociais e econômicas, a fim de reduzir as distâncias entre países desenvolvidos e em desenvolvimento. Ainda segundo a Declaração, os cuidados primários da saúde "requerem e promovem a máxima autoconfiança e participação comunitária e individual no planejamento, organização, operação e controle dos cuidados primários de saúde..." (Idem, p. 2). Também sugere a organização de sistemas de saúde com a divisão de responsabilidade entre os governos internacionais, nacionais e suas instâncias locais e regionais. Estas são as orientações que passaram a pautar o debate sobre as políticas de saúde, tendo sido transformados em "pontos básicos de agendas reformistas na área, tanto em países desenvolvidos como naqueles em desenvolvimento." (Côrtes, 2009, p. 14)

A incorporação das recomendações de Alma-Ata na formulação e implementação da política de saúde produziu diferentes estratégias e resultados ao redor do mundo, sendo que nos países de Terceiro Mundo surtiu efeitos em duas direções. No âmbito institucional, favoreceu, ao mesmo tempo, mudanças no sentido da racionalização e do surgimento de mecanismos de controle externo. Mediada pelas particularidades da mobilização política local e da orientação política dos governos, a implementação das recomendações promoveu a criação de espaços de participação com envolvimento da população no controle das burocracias e nos processos políticos, mas também gerou processos nos quais a retórica da participação cumpria papel circunscrito a contribuir com a redução de gastos "envolvendo os participantes como cofinanciadores ou como mão de obra para construção de unidades de saúde ou equipamentos sanitários" (Côrtes, 1996, p. 35).

Para Mattos (2001), a Conferência de Alma-Ata representa um marco na construção de consensos envolvendo diversos países em torno de uma política pública, cujas estratégias de implementação implicavam ampla participação do Estado. Porém o autor identifica neste evento o "último suspiro" de um mode- 
lo na dinâmica de negociações e acordos internacionais. "Talvez tenha sido a última vez que a voz dos países em desenvolvimento foi levada a sério num fórum internacional" (Mattos, 2001, p. 383).

Considerando a realização da Conferência de Alma-Ata num cenário de crise mundial e plena vigência da "Guerra Fria", torna-se importante salientar a sintonia da Declaração com as orientações políticas das agências internacionais à época. Apesar da surpresa com o papel de destaque dedicado à participação da comunidade, a lógica que permeia a estratégia dos cuidados primários é a racionalização dos recursos e a diminuição de gastos com procedimentos mais complexos e, portanto, mais caros. Mesmo a referência ao atendimento universal, seguida da priorização da atenção aos mais pobres.

Para Ugalde (1985), na América Latina o estímulo à participação da comunidade nos programas de saúde teve as mesmas finalidades ideológicas daquele observado em outros setores analisados pelo autor. É o caso de projetos experimentais patrocinados por igrejas, universidades, agências governamentais, muitos com financiamento internacional (Aliança para o Progresso, Fundação Rockefeller) em países da América Central e Colômbia. A exceção fica por conta de Cuba, onde o envolvimento da participação da população fez parte do programa da Revolução. Nos demais países latino-americanos, a participação da comunidade foi introduzida nos programas de saúde durante a década de 1970, sob a influência de agências internacionais como OMS/Opas, Usaid, Unicef e, em menor grau, o Banco Mundial (Ugalde, 1985).

Segundo o autor, muitos documentos produzidos por essas agências internacionais durante os anos 1970 dedicaram capítulos sobre a participação comunitária: Banco Mundial, em 1975, Health Sector Policy Paper. OMS e Unicef publicaram em 1977 resultados de estudos realizados em nove países sobre a participação comunitária em programas de saúde. No ano de realização da Conferência de Alma-Ata, 1978, publicação oficial do Unicef é inteiramente dedicada ao tema da participação comunitária, com ênfase nos programas de saúde. A Conferência Internacional de Cuidados Primários de Saúde realizada em Alma-Ata é apontada por Ugalde como o momento oficial da articulação entre cuidados primários e participação da comunidade. Essa articulação é reiterada no ano seguinte pela OMS como estratégica para o programa Health for all by the year 2000. Em 1981 novamente a OMS e o Unicef publicam resultados de pesquisas realizadas em sete países, sendo um capítulo completamente dedicado à participação comunitária, considerada a principal discussão 
para as agências. As citações de publicações da Opas são registradas nos anos de 1973, 1976, 1977 e $1978^{3}$.

Ugalde (1985) apresenta dados de avaliações sobre a participação comunitária nos programas de saúde obtidos em dezessete países da América Latina, cujas conclusões apontam para a baixa adesão ou resultados insatisfatórios na totalidade das situações pesquisadas.

Entre os fatores de fracasso apontados nos documentos analisados por Ugalde, sobressaem as resistências culturais de populações indígenas e tradicionais à medicina "moderna" e o risco de a organização das comunidades ser transformada em movimentos "subversivos". Em muitas das situações avaliadas negativamente, estudos citados pelo autor revelam a ausência de investimentos públicos na implantação de equipamentos e programas de atenção à saúde para a população de baixa renda, terminando por gerar situações de conflito e pressão sobre o governo (Ugalde, 1985). O autor também cita processos de cooptação das lideranças comunitárias por meio da oferta de privilégios e benefícios pessoais. Em sua visão, os governos latino-americanos aceitam acriticamente políticas a eles impostas por "ignorância" e "especialmente quando vêm acompanhadas de grandes subvenções e empréstimos" (Idem, p. 48). A partir das observações registradas, o autor considera que a manutenção de investimentos das agências internacionais por meio de consultores e acadêmicos contratados para introduzir conceitos da medicina "moderna", apesar das avaliações de resistências culturais e superstições religiosas,

3. Referências utilizadas por Ugalde: 1. United Nations. Department of Economic and Social Affairs. Popular Participation in Decision Making for Development, Nova York, 1975; 2. United Nations. Department of Economic and Social Affairs. Community Development and Related Services, 1966; 3. Organization of American States. First Interamerican Conference on Community Participation, Nova York, 1975; 4. World Bank. Health Sector Policy Paper, Washington, 1975; 5. American Public Health Association. The State of the Art of Delivering Low Cost Health Services in Developing Countries. A Survey of 180 Health Projects. Washington, DC, 1977; 6. Unicef/WHO. Community Involvement in Primary Health Care. A Study of the Process of Community Motivation and Continued Participation. Geneva, 1977; 7. World Health Organization. Formulating Strategies for Health fo All by the Year 2000. Geneva, 1979; 8. Pan American Health Organization. "Servicios comunitários de La salud y participación de la población. XXII Reunión del Consejo Directivo de La OPS". (Washington, DC, October 1973). Pub. Cientifica n. 289, Washington, DC, 1974; 9. Pan American Health Organization. "Utilización de auxiliares y Iideres comunitarios en programas de salud en el area rural". Informe final. Pub. Cientifica n. 296. Washington, DC, 1975; 10. Pan American Health Organization. Informe Del Director, Quadrienal 1974 - 1977. Anual 1977. Documento Oficial n. 158, Washington, 1978; 11. Interamerican Development Bank. Desarrollo de La comunidad: teoria y pratica 1966. 
deve-se a interesses de legitimar sistemas políticos compatíveis com os valores políticos norte-americanos.

Em meados dos anos 1980, o Banco Mundial passou a produzir estudos e pesquisas sobre o financiamento da área da saúde, cujos resultados foram publicados no documento Financing health services in developing countries: an agenda for reform (1987). No documento, o BM reconhece a importância da participação dos governos nacionais para a obtenção de resultados positivos na área da saúde após a II GM, mas adverte sobre a impossibilidade de manter o mesmo desempenho no futuro. Os argumentos apresentados defendiam a redução de responsabilidades dos Estados no financiamento da política pública, ao mesmo tempo em que buscavam dialogar com os defensores dos acordos de Alma-Ata. Em primeiro lugar, alegava o esgotamento das estratégias de mudanças comportamentais nos cuidados da saúde, uma vez que a introdução de tecnologias modernas teria minimizado a importância deste fator na melhoria da qualidade de saúde da população, reafirmando o diagnóstico com a constatação de resultados pífios nos esforços de alcançar o atendimento aos moradores pobres de regiões do interior dos países. O segundo argumento fazia referência às mudanças demográficas responsáveis pelo aumento de demanda da população adulta, exigindo maiores investimentos nos serviços assistenciais de alto custo que seriam subtraídos dos programas de atenção primária. Concluía a argumentação enaltecendo as orientações de reajuste estrutural e as medidas de diminuição de gastos públicos. As posições defendidas pelo BM encontraram forte oposição "na comunidade internacional de desenvolvimento, especialmente do Unicef” (Mattos, 2001, p. 384), pois contrariavam suas propostas de concentrar recursos na atenção às crianças.

O estímulo à participação da sociedade, na ótica das agências internacionais, não estava em sintonia com a perspectiva democratizante das lutas e mobilizações sociais que deram origem aos conselhos no Brasil. Enquanto setores da sociedade civil pressionavam pela criação de canais de participação nos processos de tomada de decisões nos assuntos de interesse público, as agências internacionais introduziam no país os pressupostos da agenda liberal, onde a participação é acionada na direção contrária.

Essa postura interpreta como negativas tanto as ênfases e políticas clássicas de corte redistributivista, como também vê com ressalvas propostas de novos instrumentos de interação entre Estado e sociedade, como é o caso dos conselhos, que possam potencializar o aumento das demandas dos bens públicos e coletivos e legitimar direitos 
sociais, sob o argumento de que isso poderia gerar ou agravar o deficit público. (Santos Júnior; Ribeiro e Azevedo, 2004, p. 13)

Côrtes (1996) aponta as dinâmicas próprias das instituições políticas e sociais como determinantes para os processos de criação de mecanismos de participação institucionalizados, como, no caso brasileiro, as dinâmicas da reforma sanitária; considera, porém, também importante a influência "que a discussão sobre mudanças nas práticas políticas nas democracias liberais teve sobre o sistema político brasileiro" (Idem, p. 36), que vivia um momento de liberalização após longo período de ditadura. A autora identifica a semelhança entre os conselhos de saúde criados no Brasil com aqueles mecanismos participativos criados nas democracias liberais durante a década de 1970.

Na opinião de Côrtes (1996), as experiências de participação inspiradas na estratégia de cuidados primários de saúde, "tiveram influência remota sobre a natureza dos fóruns que vieram a ser criados no Brasil, mas elas colaboraram para colocar na agenda do setor saúde a ideia de participação" (p. 36).

Sem discordar da autora, verificamos, por outro lado, como os debates internacionais sobre os direitos humanos e as medidas de combate à pobreza condensados nas orientações do Sistema ONU chegaram ao Brasil legitimados pela autoridade conferida às agências internacionais e sob a forma de pressão política dos países do centro do capitalismo mundial. Não era vista com bons olhos a continuidade das intensas mobilizações populares dos anos 1980, e a reconfiguração política e econômica mundial exigia a possibilidade da abertura de espaços para novos formatos de relação entre sociedade civil e Estado. No contexto das negociações e acordos antes e após a Assembleia Nacional Constituinte, as recomendações chanceladas pela ONU colaboraram com as argumentações dos setores sociais mobilizados na defesa dos projetos de democratização do Estado e da gestão das políticas públicas. Logo no início da década seguinte, o cenário foi completamente alterado, colocando em risco as conquistas de direitos inscritos na Constituição federal, ameaçadas especialmente por condicionalidades econômicas impostas ao país, sintetizadas no Consenso de Washington.

Apesar de serem avaliadas como tendo exercido influências positivas ao processo de criação dos conselhos, não podemos afirmar que tenha sido esta a perspectiva das orientações contidas na agenda do Sistema ONU, uma vez que informações sistematizadas na bibliografia analisada insistem na heterogenei- 
dade entre as agências internacionais e/ou nas concepções defendidas por seus representantes nos escritórios nacionais.

Chama a atenção as descrições das experiências de participação de usuários na área da saúde apresentadas pelos autores (Côrtes, 1996; Serapioni, 2004) que, apesar de identificarem sua origem nas recomendações das agências internacionais, não estabelecem vínculos explícitos dessa participação com as orientações de tais agências.

\section{Considerações finais}

Certamente as reflexões apresentadas neste artigo não esgotam o quadro de questões sobre as influências das agências internacionais nos processos que deram origem aos conselhos no Brasil. No entanto, ao inserir o debate sobre a experiência conselhista nesse cenário ampliado, é possível reconhecer novos elementos de análise e sugerir questões para a continuidade das investigações.

Um aspecto a ser destacado é a necessidade verificada, ao longo da história, de legitimar as medidas macroestruturais por meio do estímulo à participação. Mesmo que não ultrapasse a mera aparência de participar em atividades e processos sem o poder de influenciar decisões, o chamado à população para tomar parte em algum momento da construção de uma política ou serviço público é mais necessário ao sistema capitalista quanto maior o estágio de desenvolvimento das forças produtivas, sempre com o intuito de reduzir custos de serviços públicos. Assim, a participação significou o envolvimento da mão de obra na construção de infraestrutura e equipamentos públicos entre as décadas de 1950 até meados da de 1970. Em seguida, ganhou formatos institucionais e alguma responsabilidade na prestação de serviços e, no final da década de 1980, é explicitamente convocada a compartilhar e mesmo assumir diretamente a execução de serviços e políticas públicas.

As contradições e conflitos internos às agências internacionais, apesar da heterogeneidade de composição, são praticamente ausentes na literatura. Especialmente no que se refere à Conferência de Alma-Ata (1978), realizada na URSS, em plena vigência da Guerra Fria, articulada pela OMS e pelo Unicef. A importância a ela atribuída pelas agências internacionais nas orientações aos governos nacionais para a criação de canais de participação na área da saúde é um indicativo da necessidade de novas investigações. O pioneirismo dos con- 
selhos de saúde e suas semelhanças com as recomendações da Declaração de Alma-Ata reafirmam a importância de compreender as dinâmicas que influenciaram os processos impulsionadores da criação dos conselhos no Brasil, cuja explicitação possa jogar luzes para os desafios e impasses enfrentados por esses espaços participativos na conjuntura atual.

A pesquisa sobre os cenários internacional e nacional que deram origem aos conselhos permite afirmar a presença das agências internacionais, especialmente a partir da década de 1950, em ações políticas que visavam estimular a participação popular na implementação de projetos de desenvolvimento por elas apoiados.

Também foram verificados investimentos constantes dos organismos internacionais em processos de formação de quadros burocráticos permanentes das esferas estatais e da academia, a fim de consolidar concepções dos projetos de desenvolvimento dos países desenvolvidos, podendo ser compreendidos como parte da estratégia de cooptação para seu projeto global e de hegemonia.

A incorporação do conceito de "participação da comunidade" nos programas e projetos governamentais no Brasil e na América Latina, no contexto da ideologia desenvolvimentista, pode ser identificada como questão central a compor a agenda internacional.

Na área da saúde, na segunda metade da década de 1970, em plena vigência da Guerra Fria e da ditadura militar no Brasil, as orientações advindas da OMS/Opas cumpriram o duplo papel de legitimar propostas do movimento sanitarista nos órgãos públicos federais e oferecer a base legal utilizada pelo movimento popular de saúde nas negociações com o governo estadual de São Paulo para a criação dos conselhos populares de saúde. Em várias regiões do país, a partir de iniciativas semelhantes, setores progressistas disputavam o sentido e o significado da participação junto à população. Assim, a confluência de iniciativas promovidas por setores da Igreja Católica e da esquerda clandestina, com atuação em diferentes espaços e estratégias distintas, constituíram importantes bases de apoio à organização dos movimentos populares de saúde, que assumiram características próprias em cada região do país, de acordo com o acúmulo organizativo e as alianças estabelecidas entre as forças políticas presentes no seu interior.

A existência de sujeitos coletivos articulados no movimento de Reforma Sanitária Brasileira (RSB) favoreceu a emergência de um projeto contra-hegemônico que se contrapunha às propostas conservadoras e de caráter antico- 
munista apresentadas pelos organismos internacionais e assimilados pelas elites nacionais. A hegemonia conservadora na Assembleia Nacional Constituinte (1987-1988) provocou as alianças progressistas em torno da defesa do projeto da RSB, impulsionando assim os embates pelas conquistas da democratização da política pública e do direito à saúde, a partir do qual as disputas pela construção democrática e de alargamento de direitos na esfera pública disseminou-se, não sem contradições, para múltiplos espaços participativos que compõem a rica e desafiante experiência conselhista no país.

A investigação sobre os organismos internacionais teve como objetivo conhecer as influências exercidas nos processos desencadeados por sujeitos coletivos, em suas diferentes inserções e estratégias de lutas pela democratização no Brasil, que deram origem aos conselhos de políticas públicas. Os resultados obtidos parecem agregar novas demandas de investigações sobre a necessidade de articular a luta por direitos nos espaços próprios da sociedade civil e nos espaços institucionais estatais. O que repõe a importância de retomar e atualizar o debate sobre a "autonomia" e os riscos da "cooptação" no centro da agenda, sem contudo reeditar perspectivas de análise que dicotomizam a esfera da luta social e o âmbito da política institucional.

Recebido em 30/11/2011 • Aprovado em 10/12/2011

\section{Referências bibliográficas}

BAER, Monica; LICHTENSZTEJN, Samuel. Fundo Monetário Internacional e Banco Mundial: estratégias e políticas do poder financeiro. São Paulo: Brasiliense, 1987.

CÔRTES, Soraya V. (Org.). Participação e saúde no Brasil. Rio de Janeiro: Fiocruz, 2009. . As origens da ideia de participação na área da saúde. Saúde em Debate, Rio de Janeiro, n. 51, p. 73-79, 1996.

GADELHA, Regina M. A. F. Globalização e crise estrutural. In: DOWBOR, L.; IANNI, O.; RESENDE, P. E. A. (Orgs.). Desafios da globalização. Petrópolis: Vozes, 2002. p. 256-269. HOBSBAWM, Eric. Era dos extremos: o breve século XX: 1914-1991. Tradução de Marcos Santarrita. São Paulo: Companhia das Letras, 2006.

LIMA, Nisia T. O Brasil e a Organização Pan-Americana da Saúde: uma história em três dimensões. Cadernos de Saúde Pública no Brasil, 2002. Disponível em: <http://www.bireme.br>. Acesso: 11 mar. 2011. 
MARICATO, Ermínia. O impasse da política urbana no Brasil. Rio de Janeiro: Vozes, 2011.

MATTOS, Ruben A. As agências internacionais e as políticas de saúde nos anos 90: um panorama geral da oferta de ideias. Ciência \& Saúde Coletiva, Rio de Janeiro, v. 6, n. 2, p. 377-389. 2001. Disponível em: <http://redalyc.uaemex.mx/pdf/630/63060208.pdf>.

PAIM, Jairnilson S. Reforma Sanitária brasileira: contribuição para a compreensão crítica. 2007. 300f. Tese (Doutorado em Saúde Coletiva) — Instituto de Saúde Coletiva, Universidade Federal da Bahia. Salvador. Disponível em: <http://www.bibliotecadigital.ufba.br/ tde_busca/arquivo.php?codArquivo=576>. Acesso: $10 \mathrm{dez} .2010$.

RAICHELIS, Raquel; EVANGELISTA, Ana Carolina. Sociedade civil, questão social e relações internacionais na cidade de São Paulo. In: WANDERLEY, L. E.; RAICHELIS, Raquel (Orgs.). A cidade de São Paulo: relações internacionais e gestão pública. São Paulo: Educ, 2009.

RIBEIRO, Natalina. Sujeitos e projetos em disputa na origem dos conselhos de politicas públicas. 2011. 242f. Tese (Doutorado em Serviço Social) — Pontifícia Universidade Católica, São Paulo, 2011.

SANTOS JUNIOR, Orlando A.; RIBEIRO, Luiz C. Q.; AZEVEDO, Sérgio. Governança democrática e poder local: a experiência dos conselhos municipais no Brasil. Rio de Janeiro: Fase, Revam: 2004.

SERAPIONI, Mauro. Forme innovative di partecipazione dei cittadini Allá valutazione di qualità: citizens’ juries e comitati consultivi misti. Milano: Angeli Editori, 2004.

SILVA, Vicente G. A Aliança para o progresso no Brasil: de propaganda anticomunista a instrumento de intervenção política (1961-1964). 2008. 248f. Dissertação (Mestrado em História) — Universidade Federal do Rio Grande do Sul, Porto Alegre, 2008.

TEIXEIRA, Elenaldo. O local e o global. São Paulo: Cortez, 2001.

THE WORLD BANK. Financing health services in developing countries: an agenda for reform. Washington, DC, USA. 1987.

UGALDE, Antonio. Ideological dimensions of community participation in Latin American health programs. 1985. Disponível em: <http://www.sciencedirect.com/science/article/ pii/0277953685902862>.

WORLD HEALTH ORGANIZATION. Formulating strategies for health for all by the year 2000. Guiding principles and essential issues. Geneva: Who, 1979.

WORLD HEALTH ORGANIZATION. Primary Health Care: Report of the International Conference on Primary Health Care. Alma-Ata. Geneva: URSS, 1978. 